\title{
Inner Cannula Device
}

National Cancer Institute

\section{Source}

National Cancer Institute. Inner Cannula Device. NCI Thesaurus. Code C49859.

The inner component of a double-cannula device, designed to be easily removable and replaceable. 